TENNESSEE VALLEY AUTHORITY

Environmental Research Center

$\operatorname{man} 2803$

0 雷

ECONOMIC COSTS AND BENEFITS

ASSOCIATED WITH INVESTMENTS IN

POLLUTION PREVENTION STRUCTURES

By

G. Scott Simpson

Agricultural Economist

Land and Water Sciences

Muscle Shoals, Alabama

September 1995

DISTRIBUTON OF THIS DOCUMENT IS UMLMITED 


\section{DISCLAMMRR}

Portions of this document may be illegible in electronic image produets. Images are produced from the best available original document. 


\title{
Economic Costs and Benefits Associated With Investments in Pollution Prevention Structures
}

\begin{abstract}
About 12,000 retail fertilizer dealers distributed over 50 million tons of fertilizer materials in 1994 (TVA Commercial Fertilizers 1994). These same dealers also distribute a large percentage of all pesticides used in the United States, with pesticide consumption exceeding 500 million pounds of active ingredients in 1994 (USDA, 1994). Both fertilizers and pesticides are primary sources of surface and groundwater contamination in the United States.
\end{abstract}

The high volume of fertilizer and pesticides funneled through a relatively small number of distribution outlets has made these agribusiness sites potential sources of surface/ groundwater contamination in watersheds surrounding the agrichemical facilities. Pollutants can leave the retail sites in a number of ways, with the most common being runoff of spilled materials due to poor stewardship and/or operating practices, onsite washing of tanks and applicators without some method of collecting rinsates, or the more catastrophic occurrence of the rupture of a liquid fertilizer/bulk chemical tank.

The agrichemical industry came under increased pressures in the mid-1980s to implement environmentally sound management practices and to install containment structures around fertilizer and chemical storage/handling areas to prevent future contamination of existing sites or the movement of contaminants offsite. TVA's long and successful history of technology transfer to the retail fertilizer industry, as well as the technical expertise of the Agency's staff, made TVA ideally suited to handle the new environmental challenge.

It was during this time period that TVA's Model Site Demonstration Program (MSD) and Individual Technology Demonstration Program (ITD) were conceived. The general objective of these programs is to provide research, development, and application of pollution prevention technologies and strategies for industries which market or use fertilizers, pesticides, and other agricultural chemicals. These programs, and the pollution prevention technologies advanced by them, have made a very positive impact on the U.S. agrichemical industry since their inception. To date, TVA has 62 MSD/ITD sites in 27 states in which TVA recommended pollution prevention technologies and operating practices have been implemented (figure 1).

Perhaps the most important indicator of the worth of a any new technology is if the user is better off after its adoption than before, especially when adoption is mandated rather than voluntary. From an economic perspective, the installation of pollution prevention structures, as well as adherence to other regulatory requirements, such as reporting, carries a real cost to the agrichemical retailer. However, there may also be benefits tied to the adoption of new technology, some tangible and some intangible, that would offset some or all of the additional operating costs accrued as a result of investment in the environmental technology. This paper attempts to document the economic costs 
Figure 1

Geographic Locations of Pollution Prevention Research/Demonstrations for Agricultural Retailers

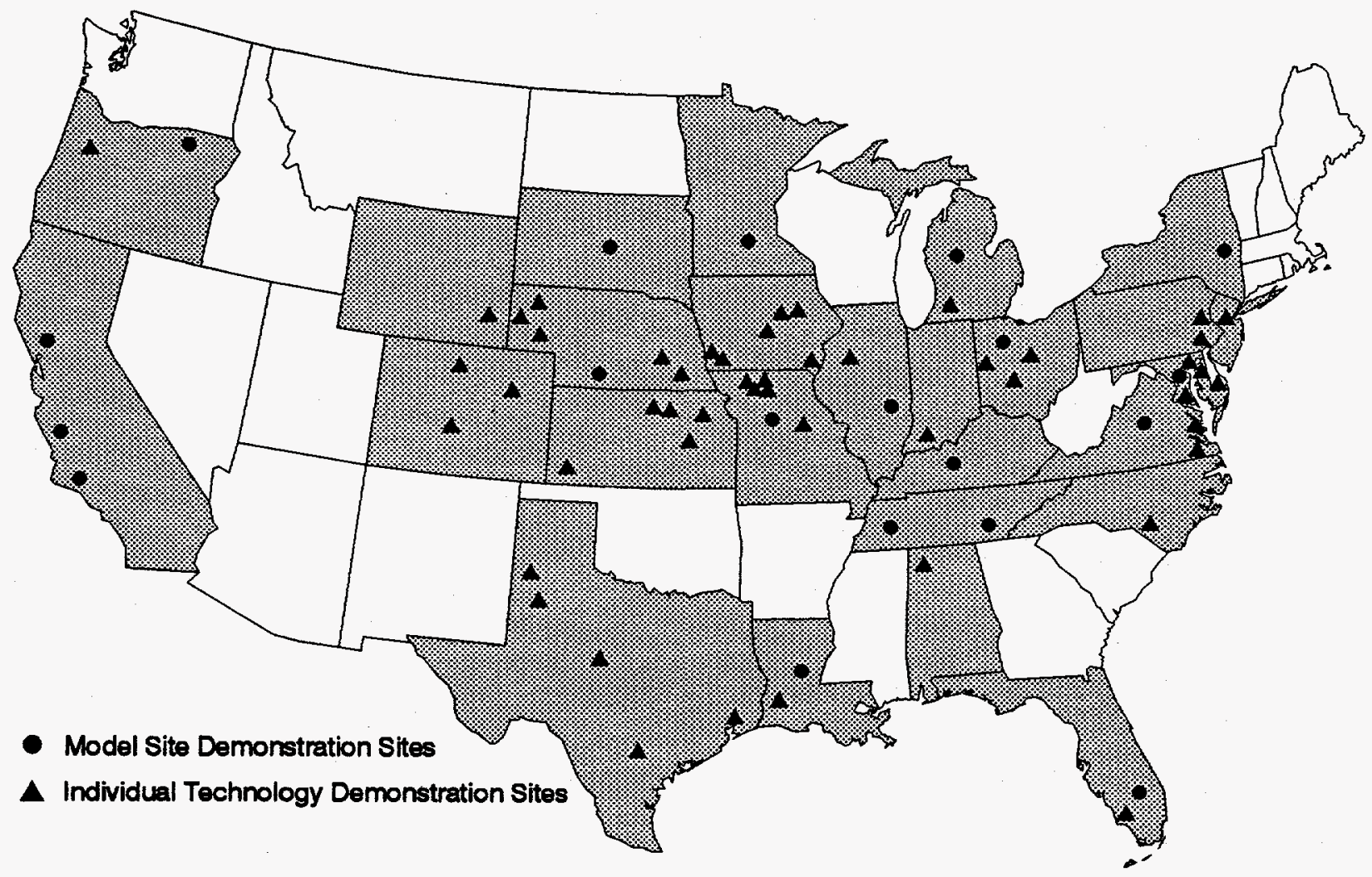


associated with investments in pollution prevention technologies and adherence to environmental regulations at TVA demonstrator sites; as well as the potential benefits an agribusiness dealer may accrue as a result of the environmental investment.

To document the economic impact at the agribusiness dealer level, a questionnaire was sent to all MSD/ITD demonstrators as well as to about 50 fertilizer dealers to whom TVA has provided some form of environmental assistance without benefit of formalized contracts. The data collected included the initial investment and annual cost per ton associated with pollution prevention structures as well as the perceived benefits that had accrued as a result of the environmental investment. A total of 27 demonstrators responded to the survey.

\section{DEMONSTRATOR CHARACTERISTICS AND THE ANNUAL COST OF FERTILIZER OPERATIONS}

The demonstrators who responded to the survey typically were large, independent, multiproduct (fluid and dry materials) dealers. Just over half of the respondents were independent dealers, 20 percent were corporately owned, and the remaining 25 percent were cooperatives.

The demonstrators had an average asset value of $\$ 428,000$ in fertilizer-related equipment and $\$ 320,000$ in application equipment, making a total asset value of $\$ 748,000$. The average replacement value of these assets was estimated to be roughly $\$ 1.3$ million. The average age of fertilizer-related equipment was 9.1 years, while age of the application equipment averaged 6.5 years.

The annual fertilizer tonnage sold by the demonstrators by product type is listed in appendix $A$ and is shown graphically in figure 2 on the following page. Data represent responses from 18 dealers who reported both tonnage sold and detailed costs associated with their pollution prevention structures. Most of the dealers (16) reported sales of both dry bulk and liquid nitrogen fertilizers. Tonnages of these two materials accounted for 144,771 tons or 64 percent of the total. Suspensions and other fluids accounted for 12 and 13 percent, respectively, of the total, with about half the respondents reporting sales. Ammonia accounted for 8 percent of the total, with 66 percent of the dealers reporting sales. Dry bagged fertilizers accounted for only 2.5 percent of the total, with 9 dealers reporting some tonnage in this product category.

Annual costs for all fertilizer and chemical operations were reported by 14 dealers. Total annual cost for the 14 respondents was $\$ 12,373,853$, with 74.9 percent of the total $(\$ 7,269,897)$ being allocated to fertilizer operations and 25.1 percent being allocated to chemical operations. The total tonnage reported by the respondents was 166,153 tons, resulting in an average production cost of $\$ 43.75$ per ton. The median cost of production was $\$ 41.27$ per ton. Figure 3 on the following page illustrates the estimated annual cost of fertilizer production for the 14 demonstrators reporting. 




\section{INVESTMENTS IN POLLUTION PREVENTION STRUCTURES}

Pollution prevention structures, by definition, are designed to prevent or greatly reduce the possibility of a release of contaminants into the surrounding environment. Typical examples of pollution prevention structures and/or technologies that TVA has recommended for use in agrichemical facilities include:

- Containment for fluid fertilizers and pesticides.

- Containment around liquid material transfer points, such as load or wash pads.

- Containment around dry material transfer points, such as material loading/unloading and mixing areas.

- Facility redesign (when possible) to achieve environmental and production efficiencies.

- Implementation of environmental best management operating practices.

Containment for fluid fertilizers and pesticides usually involves some form of diking. TVA has typically recommended concrete to form these relatively small containment areas. However, economics usually dictate that containment for large tanks, with capacities over 100,000 gallons, be constructed using earthen dikes, synthetic liners, high-clay content soils, or other soils which meet permeability standards.

A load pad is used to contain fluid materials around material transfer points. Load pads are usually made of concrete and are sloped so that spilled liquids will drain into a sump. Materials collected in the sump are then pumped to holding tanks from which they can be recycled into the production process, sold as a lower-analysis mixture, or land applied. The load pad can also be used by the dealer to wash down application vehicles after use; however, TVA recommends that a separate wash pad be installed. TVA has recommended that where possible these pads should be covered to reduce problems associated with stormwater collection and management.

Spillage of dry materials usually occurs near the blending area; between the blending area and dry storage; or at points where the dry materials are transferred into storage by either truck, rail, or barge. Typically, dry materials can be contained with concrete pads at these transfer points. The concrete prohibits movement of the dry materials and also affords easy cleanup.

Once pollution prevention structures are in place, the dealer then must implement management practices to assure that the facility is operated in an environmentally safe manner. A partial listing of issues the agrichemical dealer must now address include: stormwater management, concrete coating recommendations, the recycle of waste materials, disposal of pesticide containers, where and how pesticides are to be mixed, applicator washdown after use, emergency response plans, employee training, employee safety, security, maintenance of pollution prevention structures, general site stewardship, and nutrient management plans in some areas of the United States. Whenever the 
opportunity arises, TVA will advise plant management on physical layout considerations that will maximize both environmental and production efficiencies.

The investment required to bring any agrichemical site into environmental compliance can and does vary greatly depending upon such factors as: (1) past and current operating practices, (2) the age of the facility, (3) the agrichemical materials sold at the plant, and (4) the original plant design and construction. Typically, the TVA engineer will assess the agrichemical site to determine the most cost-effective way in which existing facilities can be modified to bring the entire site into environmental compliance.

Total investment in pollution prevention structures by the 27 demonstrators reporting was $\$ 4,940,070$. Twenty-two respondents indicated that additional expenditures of $\$ 2,204,000$ (total) would be required to bring their facilities into full regulatory compliance. The average current and future investment cost was reported to be $\$ 182,966$ and $\$ 100,182$, respectively. The median current investment was $\$ 100,000$ and the median future investment value was $\$ 45,000$ (see figures 5 and 6 on following page). The relatively large difference between average and median values suggests that the data are substantially skewed to the left, meaning that the median values may be a better indicator of typical investments, current and future, by most TVA demonstrators. About eighty percent of the respondents had also made noncapital expenditures (e.g., training, etc.) averaging $\$ 13,750$ per location.

If it is assumed that the expenditures made by the 27 respondents are representative of the $35 \mathrm{MSD} / \mathrm{ITD}$ dealers who did not return questionnaires, then the total investment at all MSD/ITD locations would be approximately $\$ 16.3$ million, $\$ 11.3$ million in current expenditures and $\$ 5.0$ million in future expenditures.

A linear regression was run to determine if a statistical correlation existed between the size of demonstration, measured by annual tonnage, and environmental expenditures. Results indicated that the correlation coefficient $\left(r^{2}\right)$ was only 0.12 , suggesting very little correlation. The primary reason for the low correlation can probably be attributed to the four factors listed at the top of the page. Agrichemical sites do differ and each of these factors will impact the difficulty and the cost that must be incurred to bring a plant into compliance from an environmental standpoint. For example, a relatively new 10,000-ton facility with good management and operating practices in place may require less environmental investment than will a 5,000-ton older facility where past operating practices are environmentally questionable. 


\section{Figure 4 \\ Total Expenditures for Pollution \\ Prevention Structures Installed}

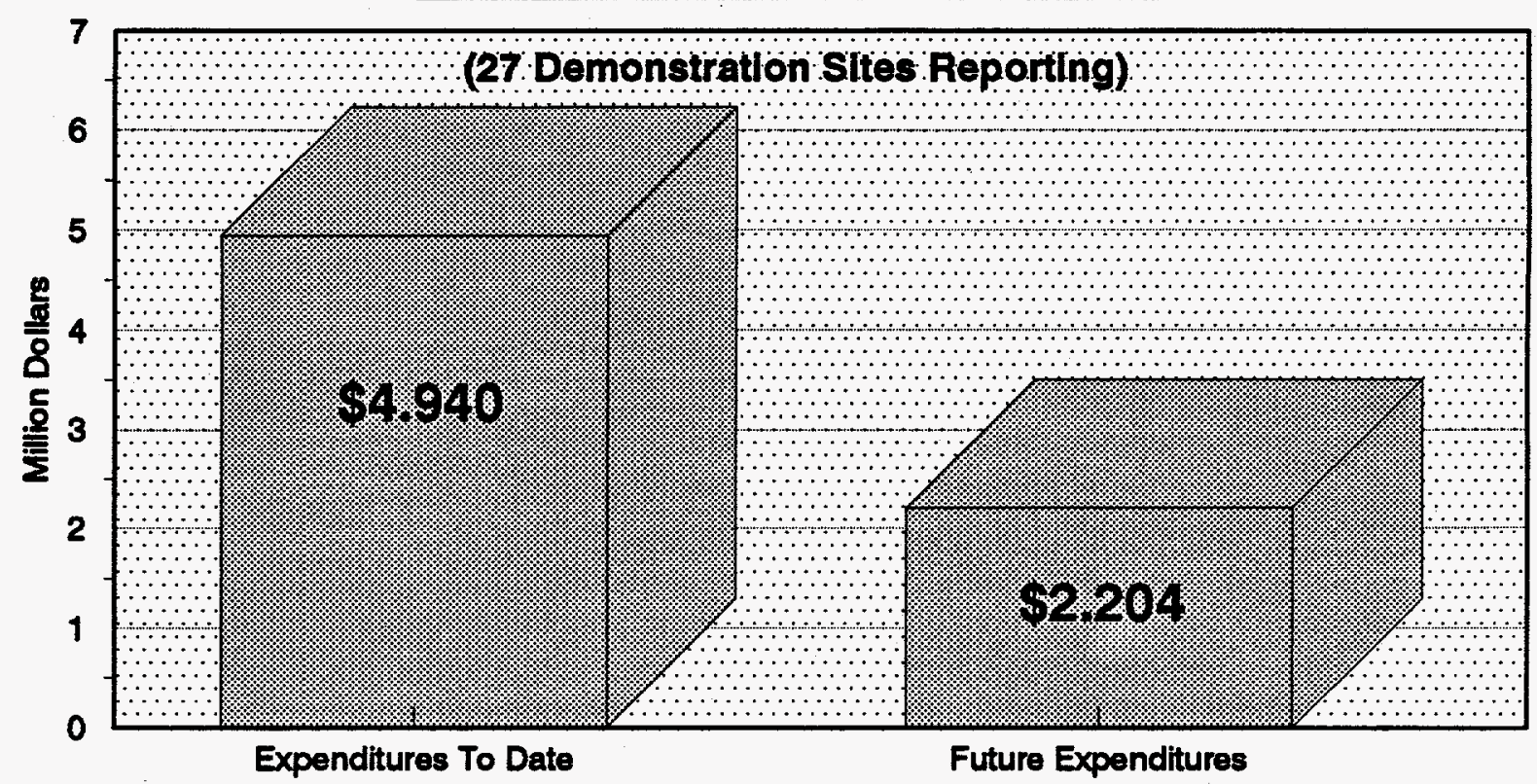

Figure 5

Average and Median Expenditures for Pollution Prevention Structures Installed

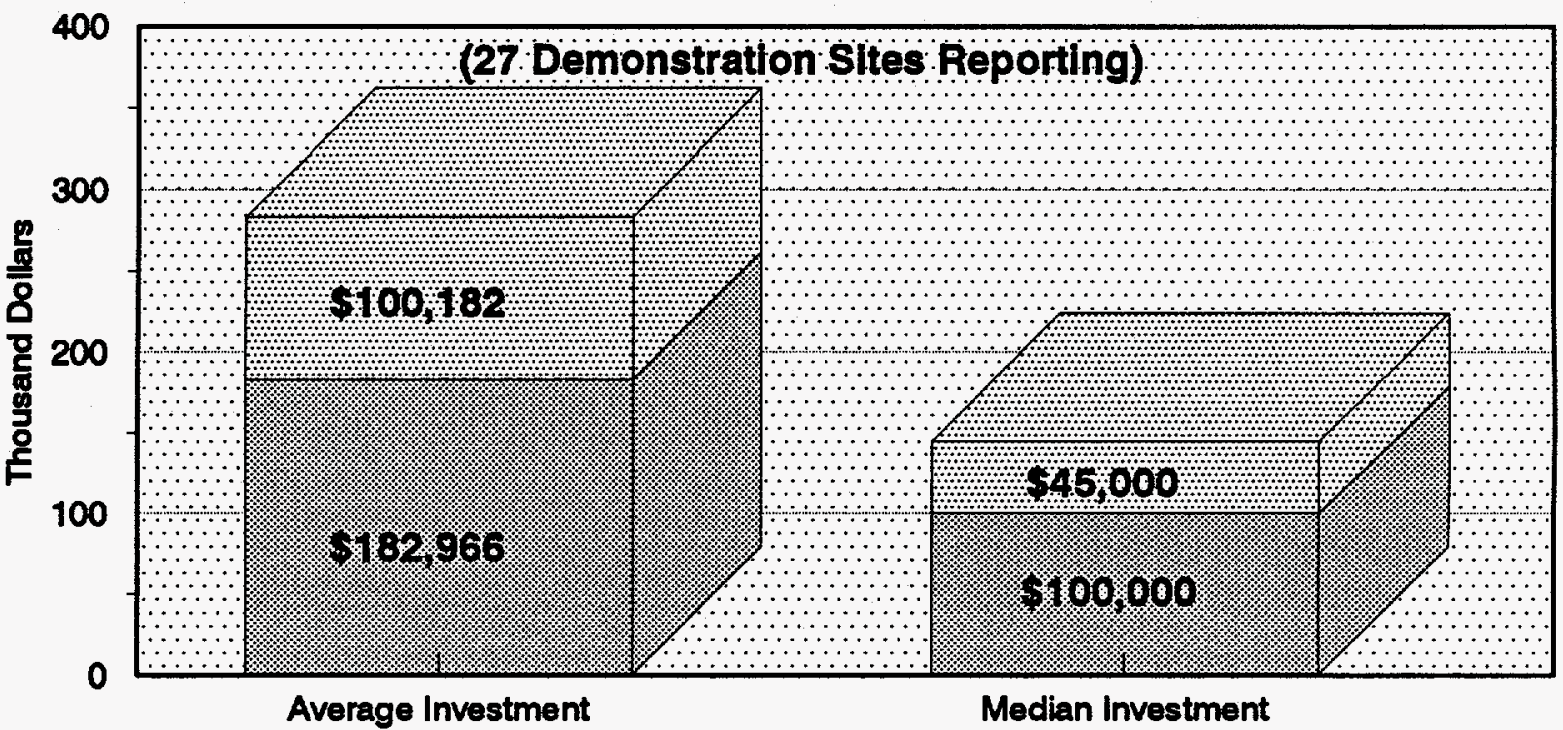

Current Investment : Future Investment 


\section{ANNUAL COST OF POLLUTION PREVENTION STRUCTURES/ENVIRONMENTAL REGULATIONS}

Data on the annual cost of environmental structures/regulations were reported by 18 demonstration dealers. The annual environmentally related costs were broken out of existing dealer expense accounts and categorized as relating to: (1) salaries and wages, (2) maintenance and repairs, (3) insurance, (4) depreciation, or (5) general office/business/miscellaneous.

The average annual cost of investments in pollution prevention structures and of other items relating to environmental regulations for the 18 demonstrators reporting was $\$ 4.83$ per ton of product sold. This average is based on total environmental costs of $\$ 1,093,280$ and a total annual throughput of 226,408 tons for the dealers reporting. The median cost per ton was $\$ 4.61$. These data are presented in appendix $E$ and in figures 7 and 8 on the following page.

Salaries and wages allocated as environmental costs include time spent by employees and plant management in: (1) repairing, maintaining, and cleaning pollution prevention structures; (2) preparing environmental reports; and (3) managing any environmentally related matters. The total annual cost of salaries and wages associated with pollution prevention structures and complying with regulations was $\$ 332,988$. This is equal to $\$ 1.47$ per ton of product sold or 30.5 percent of total annual environmental costs.

Maintenance and repair cost for environmental structures is defined as the cost of materials used to repair these structures. Maintenance and repair costs totaled $\$ 78,038$ and were reported by 16 dealers. The average cost was equal to $\$ 0.34$ per ton or 7.1 percent of total annual environmental costs.

A portion of total insurance costs can usually be allocated as an environmental cost. Environmental insurance costs were reported by 17 dealers and totaled $\$ 83,548$--an average cost of $\$ 0.37$ per ton of product sold or 7.6 percent of annual environmental costs.

Annual depreciation cost associated with pollution prevention structures was the largest single expense item, as was expected, and totaled $\$ 395,294$. Depreciation costs were reported by all 18 demonstrators. The average depreciation cost was $\$ 1.75$ per ton of product sold or 36.2 percent of the total annual environmental costs.

General office/business/miscellaneous expense is a "catch all" category. The expenses reported in this category include such items as interest expense, office supplies, postage, contractual costs, legal expenses, ground or water sampling, site improvement costs, and any other expense incurred as a result of environmental investments or regulations. These expenses totaled $\$ 203,412$ and were reported by 17 demonstrators. The average cost was $\$ 0.90$ per ton of product sold or 18.6 percent of the total environmental expenses. 

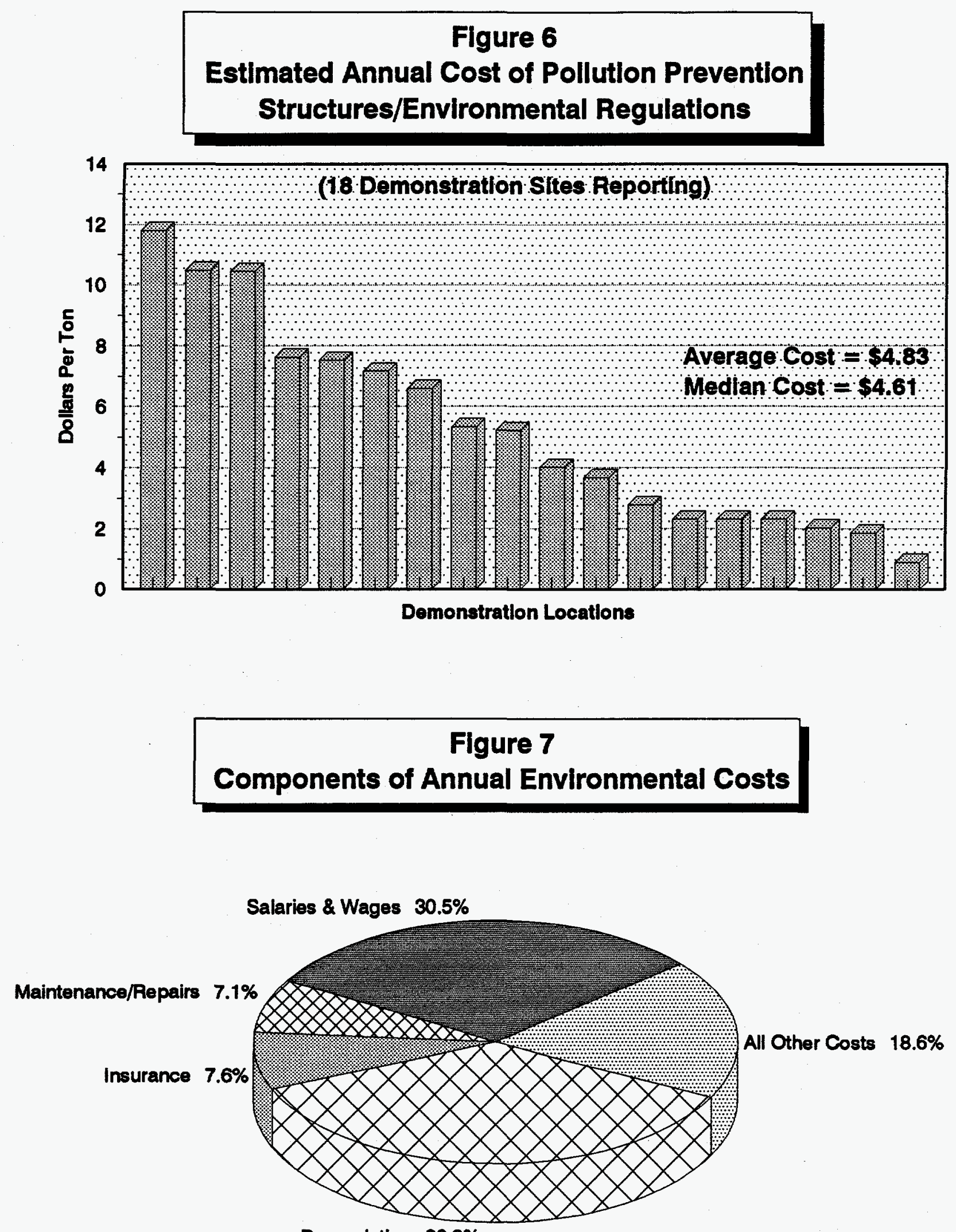

Depreciation $36.2 \%$ 


\section{BENEFITS ACCRUED FROM INSTALLATION OF POLLUTION PREVENTION STRUCTURES}

A number of benefits, both tangible and intangible, may be realized as a result of investments in pollution prevention structures and in adopting environmentally sound operating practices. Both tangible and intangible benefits can only complement other profit management strategies utilized by plant management and thus add to the percentage of environmental costs that can be offset.

\section{Tangible Benefits}

Thirty-seven percent of the dealers reporting indicated that they had experienced a decrease in product loss since pollution prevention structures and environmental operating practices were put in place. Eight dealers reported an average reduction in product loss of $\$ 3,412$ per year.

Only two demonstration dealers reported a reduction in insurance costs resulting from the installation of pollution prevention structures. Both dealers reported a cost reduction of $\$ 5,000$. While only two demonstrators have experienced decreased insurance costs thus far, the fact that these two have done so would indicate that such possibilities are there for everyone.

Seventy-five percent of the dealers reported that they had received rebates from chemical companies. Typically, these rebates are received when containment around chemical storage is constructed. Data on the rebate amounts were not collected.

Eighty percent of the dealers responding reported an increase in product sales (tonnage) since completion of pollution prevention structures. On average, 27 percent of increased sales volume was attributed to environmental site improvements and 73 percent of the increase was attributed to market factors. Typically the increase in annual tonnage resulting from environmental site improvements can be traced to a higher, or more positive customer perception of the agribusiness and its management. Assuming these dealers had a positive initial margin, these increases in tonnage sold will result in higher dealer profits.

Fifty percent of the dealers reported that plant efficiency had increased as a result of changes made in the physical layout of their plant to accommodate pollution prevention structures. These layout changes improved traffic flow and streamlined mixing and loadout to the extent that production and application efficiencies were achieved. In effect, these dealers increased their daily production which translates into less idle-time for application resources, less overtime costs, and, more importantly, greater production capacity in abbreviated fertilizer seasons. Also, greater employee productivity proved to be a product of cleaner and more efficiency-oriented working conditions. Increased production and employee productivity also translate directly into higher profit levels. 


\section{Intangible Benefits}

Intangible benefits involve public, customer, and even employee perceptions about the business unit. The installation of pollution prevention technologies and operating procedures make positive statements about the agrichemical plant, dealership management, and the dealer's commitment to the future. This type of "professionalism" can be readily marketed, and, in turn, can translate into increased tonnage sold and higher profits.

Positive perceptions reported:

- Seventy-four percent of the dealers responding reported that farmers/customers had a higher regard for their businesses since construction of pollution prevention structures.

- Fifty-six percent of the dealers reported that they believed the community or general public's perception of their business was more positive since environmental investments had been made.

- Six dealers who responded have received environmental awards for pollution prevention measures taken at their facilities. In total, $15 \mathrm{MSD} / \mathrm{TTD}$ dealers have received environmental awards. One MSD dealer won an additional award for pollution prevention structures and practices put in place at one of his other plant sites. He patterned environmental measures implemented there after his TVA-designed model site. These awards can be used as marketing tools by the demonstrators.

- Fifty-two percent of the dealers reported that improved customer perception of the business, as a result of environmental technologies installed or awards received, had led to an increase in product sales.

- Sixty-eight percent of the dealers reported that employee morale had increased as a result of environmental improvements and changes made in operational procedures.

- Ninety-six percent of the managers reported that their own peace-of-mind had increased as a result of environmental improvements and changes made in operational procedures.

\section{SUMMARY}

Fertilizers and pesticides are a major source of surface and groundwater contamination in the United States. The agrichemical industry came under increasing pressures in the mid 1980 s to implement environmentally sound operating practices and install containment structures around fertilizer and chemical storage/handling areas to prevent contaminants 
from moving offsite into adjoining watersheds. This led to the implementation of TVA's model site and individual technology demonstration programs.

The general objectives of these programs have been to provide research, development, and application of pollution prevention technologies and strategies for industries that market or use fertilizers, pesticides, and other agricultural chemicals. To meet these objectives and aid in the transfer of environmental technologies, 62 pollution prevention research/demonstrations have been established in 27 states.

Total investment in pollution prevention structures by the 27 demonstrators reporting was $\$ 4,940,070$. Twenty-two respondents indicated that additional expenditures of $\$ 2,204,000$ would be required to bring their facilities into full regulatory compliance. The average current and future investment cost was reported to be $\$ 182,966$ and $\$ 100,182$, respectively. The median current investment was $\$ 100,000$ and the median future investment value was $\$ 45,000$. The average annual cost of these pollution prevention structures installed was $\$ 4.83$ per ton of throughput. The median cost was slightly lower at $\$ 4.61$ per ton.

Benefits associated with environmental investments, as reported by the demonstration dealers, included: lower shrinkage costs, lower insurance costs, rebates from chemical companies, increased production and application efficiencies, and increased annual tonnage of product(s) sold, with the latter resulting from improved and more positive customer perception of the agribusiness unit.. Thus, the tangible and intangible benefits associated with environmental investments and improved management/operational practices combined with other profit management strategies may offset a high percentage of the increased annual costs resulting from environmental investments.

The "close to neutral" benefit-cost ratio makes the "mandated" environmental investment by some agrichemical dealers more palatable and in the long run should increase the economic value of the business operation. And there is strong indication that it may actually encourage environmental investments by agrichemical dealers in states where environmental regulations are not yet in place or where regulations are currently being considered. 


\section{SOURCES OF INFORMATION}

Foster, Thomas H., and G. Scott Simpson. "Estimated Ownership and Operating Costs for Selected Types of Retail Fertilizer Facilities-An Update." Indiana Plant Food and Agricultural Chemicals Association, Inc., Indianapolis, Indiana, January 1980.

Simpson, G. Scott. The Impact of Investments in Environmental Containment on Retail Dealer Costs and Returns. TVA Circular Z-270, August 1990.

Simpson, G. Scott. Evaluation of TVA 's Model Site and Individual Technology Pollution Prevention Demonstration Programs and Their Impact on the Agrichemical Industry. TVA Circular Y-240, June 1995. 


\section{APPENDIXES}




\section{APPENDIX A}

Annual Tonnage Sold by Type of Product at 18 Demonstration Sites

\begin{tabular}{lcccr} 
Product & $\begin{array}{c}\text { Demonstrators } \\
\text { Reporting }\end{array}$ & $\begin{array}{c}\text { Total } \\
\text { Tonnage }\end{array}$ & $\begin{array}{c}\text { Weighted } \\
\text { Average } \\
\text { Tonnage }\end{array}$ & $\begin{array}{c}\text { Percent } \\
\text { of Total }\end{array}$ \\
\hline Dry bag & 9 & 5,376 & 299 & 2.4 \\
Dry bulk & 16 & 97,823 & 5,435 & 43.2 \\
Liquid nitrogen & 16 & 46,948 & 2,608 & 20.7 \\
Suspensions & 9 & 29,705 & 1,650 & 13.1 \\
Other fluids & 9 & 28,001 & 1,556 & 12.4 \\
Ammonia & 12 & 18,555 & 1,031 & 8.2 \\
\hline Total tonnage & & 226,408 & 12,578 & 100.0 \\
\end{tabular}




\section{APPENDLX B \\ Estimated Annual Cost of Pollution Prevention Structures/Environmental Regulations at 18 TVA Model Site and Individual Technology Demonstrations}

\begin{tabular}{|c|c|c|c|c|}
\hline Expenses & $\begin{array}{r}\text { Total } \\
\text { Annual } \\
\text { Cost } \\
\end{array}$ & $\begin{array}{c}\text { Demonstrators } \\
\text { Reporting } \\
\text { Costs }\end{array}$ & Cost/Ton & $\begin{array}{c}\text { Percent } \\
\text { of Total } \\
\text { Cost }\end{array}$ \\
\hline Salaries and Wages (1) & $\$ 332,988$ & 18 & $\$ 1.47$ & 30.5 \\
\hline Maintenance and Repairs (2) & $\$ 78,038$ & 16 & $\$ 0.34$ & 7.1 \\
\hline Taxes and Insurance & $\$ 83,548$ & 17 & $\$ 0.37$ & 7.6 \\
\hline Depreciation & $\$ 395,294$ & 18 & $\$ 1.75$ & 36.2 \\
\hline Other Environmental Expenses (3) & $\$ 203,412$ & 17 & $\$ 0.90$ & 18.6 \\
\hline Total Environmental Expenses & $\$ 1,093,280$ & & $\$ 4.83$ & 100.0 \\
\hline Total Tonnage Sold & 226,408 & & & \\
\hline
\end{tabular}

1. Includes time spent by employees and management in: (1) repairing, maintaining, and cleaning pollution prevention structures; (2) preparing environmental reports; and (3) managing other environmentally related matters.

2. The cost of materials used in the repairs and maintenance of pollution prevention structures.

3. Other environmentally related expenses. Includes, but is not limited to, such items as: (1) interest expense associated with environmental structures, (2) office supplies or expenses incurred in the preparation of environmental reports, (3) legal expenses regarding environmental matters, (4) soil and/or water sampling costs, (5) site improvement costs, and (6) any other environmentally related costs. 